\title{
GCU
}

Glasgow Caledonian

University

University for the Common Good

\section{Overview of on-line and off-line ampacity identification techniques of bare overhead transmission line}

Abdael Baset, Abdallah; Farrag, M. Emad; Farokhi, Shahab; Hepburn, Donald M.

Published in:

2016 51st International Universities Power Engineering Conference (UPEC)

DOI:

10.1109/UPEC.2016.8113979

Publication date:

2017

Document Version

Author accepted manuscript

Link to publication in ResearchOnline

Citation for published version (Harvard):

Abdael Baset, A, Farrag, ME, Farokhi, S \& Hepburn, DM 2017, Overview of on-line and off-line ampacity identification techniques of bare overhead transmission line. in 201651 st International Universities Power Engineering Conference (UPEC)., 161, IEEE, pp. 1-4. https://doi.org/10.1109/UPEC.2016.8113979

\section{General rights}

Copyright and moral rights for the publications made accessible in the public portal are retained by the authors and/or other copyright owners and it is a condition of accessing publications that users recognise and abide by the legal requirements associated with these rights.

Take down policy

If you believe that this document breaches copyright please view our takedown policy at https://edshare.gcu.ac.uk/id/eprint/5179 for details

of how to contact us. 


\section{Overview of On-line and Off-line Ampacity Identification Techniques of Bare Overhead Transmission Line}

\author{
Abdallah Abdaelbaset \\ Glasgow Caledonian \\ University, \\ Abdallah.Baset@gcu.ac.uk
}

\author{
M Emad Farrag \\ Glasgow Caledonian \\ University, \\ Mohamed.Farrag@gcu.ac.uk
}

\author{
Shahab Farokhi, \\ Glasgow Caledonian \\ University, \\ shahab.farokhi@gcu.ac.uk
}

\author{
Donald M Hepburn, \\ Glasgow Caledonian \\ University \\ dmhe@gcu.ac.uk
}

\begin{abstract}
The economics of power transmission requires operators to maximise the power through the network. Increasing knowledge of the impact of environmental factors on the current carrying capabilities of bare wire overhead lines is, therefore, important. Cost savings resulting from enhancing thermal transfer capabilities of transmission lines has motivated many utilities and power systems research centres to investigate techniques for maximising operational parameters. Enhancing power ratings of bare power conductors brings, alongside improved generated power dispatch flexibility, cost savings and economical and technical challenges. The aim of this paper is to examine some of the existing techniques employed to compute the ampacity of bare power lines and discuss practical limitations of these techniques. In addition, the impact of each technique will be considered from an operational prospective.
\end{abstract}

On-line and off-line techniques are summarised and compared based on the nature and quality of power sources connected to the system, e.g. power output of windfarms tends to be of intermittent nature.

Index Terms - Ampacity of bare power lines, dynamic thermal ratings, generation dispatch, ruling span of transmission line and thermal time constant.

\section{INTRODUCTION}

Improvements in efficiency and rapid growth of new generations of wind turbines, combined with increased power flow from distributed generation equipment, has increased the complexity of operation of power networks. The existing power grid infrastructure must incorporate methods to maximise use of the system components safely, particularly on the ampacity of bare overhead power lines during high wind generation periods.

To maximise investment in areas of high wind profile, existing wind farms locations are likely to attract more wind farms developers or incentivise existing wind farm owners to increase their transmission entry capacity (TEC). Traditionally these increases have been accepted by the network operating companies upon a developer's acceptance of an active inter-tripping scheme: in order to protect an overloaded transmission sector or circuit, a generator would be disconnected from the system shortly after receipt of control signal from a transmission system operator. Clearly this method of operation/disconnection causes both wind farm and power grid operator to lose revenue stream during ideal wind generation conditions. This situation may also result in the need to dispatch generation from elsewhere in the system, consequently increasing system transfer costs and losses.

A practical approach to mitigate such events would be through investigation of opportunities to enhance transmission line ratings, giving the possibility of short term high current transmission. An increase in wind speed which causes significant increase in generated output from the connected wind farms in a particular locality is likely to coincide with an increase in ampacity of transmission circuits, because ampacity of bare power lines is a function of wind speed [1].

Taking an overly conservative approach towards computing a power line conductor's ampacity, will result in

- Underutilisation of power lines

- Missed generation potential and

- Whole host of operational and power dispatch challenges during both steady-state and adverse weather conditions.

On the other hand, overestimating thermal capability of power lines can cause undue damage to conductors and associated hardware, resulting in costly lengthy outages and repairs.

Research in this area was divided into two main categories, first, considering the aspect of use of real time data collection at important locations, via a Supervisory Control and Data Acquisition (SCADA) telecommunications interface to regional and local control centres. The second was directed towards understanding the thermal behaviour and characteristics of different power conductor technologies in response to its environment, e.g. how ambient air temperature, humidity, rain, wind and dust affected the thermal behaviour of the conductors.

\section{MAIN AIM OF AMPACITY COMPUTATION}

Power transmission companies compute the ampacity of their plants, cables and power lines to gain an understanding of the possible interaction of the various sections of their infrastructure. The thermal limits of power lines, in particular, are the main constraint that will impact on the development of a proposed electrical generation project. It also helps increase revenue streams through more efficient use of the transmission network and, hence, reduces the overall cost of power transmission to consumers. Increasing confidence in computing power lines ampacity just by few percent results in significant cost savings. 
The main objective of ampacity computation techniques and algorithms is to investigate the effect of power line heating and resulting thermal expansion. Any increase in current in a conductor will produce heat which, in case of bare power lines, has to be dissipated into air. Aluminium alloy conductors, which currently forms the vast majority of the existing power transmission assets in Europe, have a tendency to anneal at high temperatures [2]. Annealing of conductors leads to loss of their mechanical integrity and results overtime in deformation of conductors. In addition, for economical generation dispatch reasons, there is a need to perform transient thermal analysis to maintain security of supplies for power importing customers during adverse weather conditions. These are called emergency ratings and they are computed by system operators based on mechanical and thermal behaviour of overhead power lines and their associated hardware during heavy loading conditions, both physical load of snow and ice on the cables and electrical load due to customer needs.

\section{TYPES OF ON-LINE AMPACITY COMPUTATION}

Operational costs associated with on-line ampacity identification techniques have, until recently, made these economically questionable for power transmission companies. Advances in telemetry technology, however, has prompted system operators to consider using these techniques with caution. Unlike on-line ampacity identification techniques of bare power lines, off-line techniques have offered value for money solutions but they require power companies to have extensive training for control engineering, network planners and generation dispatch personnel. Five of the methods are described below.

\section{A. Line sag monitoring}

It has been shown that it is possible to determine a transmission line rating based on the relationship between conductor's temperature and line sag using transmission line tension monitoring system, an increase in temperature of conductor, will result in its thermal expansion because[3]

$S a g=\frac{w L^{2}}{8 T}$.

Where, $W=$ Weight per unit length of conductor.

$L=$ Length of span, $T=$ Tension in conductor

Drawbacks of employing such a system is that it requires the Transmission line being considered, must be constructed from towers of the suspension type and there should be few towers providing tensioning at corners. This line structure is not practical on many routes, because position of towers on a line route is determined by topography and cost of the land. Application of this technique for existing long transmission lines becomes questionable. As many of transmission lines run through elevated landscape exposing them to severe weather conditions, calibration of these monitoring systems becomes a challenge, over dependence on these systems during heavy loading conditions could cause undue pressure on power lines or on power line hardware.

\section{B. Conductor temperature monitoring}

Researchers in [4][5] suggest employing line temperature sensing technologies combined with real time weather data and a custom built routine software to provide knowledge of ratings of transmission lines and other system components in real time. Transfer of real time data can be through employing either a leased communication line or a "SCADA" link.

Drawbacks of this approach can be summarized as follows:-

i. High associated costs of installation, operation, calibration and maintenance.

ii. Thermal impact of enhancing the conductor's ratings on conductor hardware and conductor structure needs to be reviewed, costs associated with system outages needed to strengthen towers and construction costs to match increased ratings are likely to be very high.

iii. Difficult to implement as it requires constant manual updating which may not allow system operator to fully utilise system capabilities in real time during high loading conditions (unless purpose built software is integrated into the main control system to fully automate the decisionmaking process).

A solution to all of the above side effects could be achieved by employing the thermal monitoring functionalities available in new distance relays. However, this may not be practical in hybrid circuits, i.e. where part of the route consists of overhead line and part of underground cable. This due to the limited tolerance of cables to increase in conductor temperature and the fact that weather conditions have less effect on underground cables thermal behaviour compared to overhead bare conductors.

Practical monitoring and generation dispatch issues have to be considered. Thermal plants often take a number of hours to heat up and start running at full capacity, thermal allowances allocated to a particular transmission line may have changed by then, extreme caution is needed when dynamic line ratings is employed.

Within a transmission line there may be a few spans which are strung above a thermally constrained terrain e.g. a motorway or a river crossing. This may add to the complexity of the Dynamic Line Rating (DLR) algorithm. Many power systems operators have expressed their concerns about the reliability of data which has been extracted using sensing equipment deployed in harsh elevated terrains. In these situations environmental factors, such as rain, dust and ice, tend to affect recorded and transmitted readings. Over dependence on this additional sensing equipment may result in non-ideal operation, to the detriment of existing assets.

\section{Line sag monitoring using Global Positioning System}

Application of a global positioning system (GPS) to measure conductors sag and determine real time rating was the method applied in [6] and [7]. Their assumptions are based on 
experience which dictates that the clearance of an overhead line is the key factor limiting its thermal capacity, particularly in areas of high interconnections. Although this is true in some cases, there are other factors to be considered, as discussed below:

Although the degree of sagging, as indicated to a central control room by the GPS monitoring system, may be within tolerated values, other transmission equipment's thermal limits may not have been considered in this approach. The impact of additional factors, such as overhead line disconnector silver plating wear due to exposure to high temperature and thermal capability of line protection current transformers, must also be taken into account. Lack of calibration of this system may cause failure of the additional components; resulting in outages and costly equipment purchase and installation costs. Other potential problems of moving to this type of system could be the failure of equipment caused by the delay of other routine maintenance activities which may take place during line sag inspections.

Measuring sag of only one phase conductor as suggested in [5] can prove to be a very costly and dangerous way to approach DLR, because by the time one phase conductor has sagged beyond an acceptable level, other phase conductors may have exceeded and encroached on safety clearances before the monitored phase. Therefore reliance on a single phase may give a false indication to system operator. Single phase faults are very common in transmission systems.

Potential radio frequency interference (RFI), "electronic noise", would be caused by the power system's protection data being sent through radio communication channels. System developers would have to employ filter circuits to mitigate RFI impacts.

Deploying a GPS-based sag measurement system would require system's control engineers to have a detailed geographical knowledge of all remote areas to be able to dispatch transmission response commands, such as breaking jumpers off teed transmission circuits to minimize losses. A DLR system developer would also be required to produce a complex, detailed map displaying acceptable safety encroachment distances along the transmission line in question.

\section{Active dynamic line rating}

An active dynamic line rating (ADLR) study, which uses multi-station data to consider the weather parameters around a power line and data on real time conductor surface temperature, is presented in [7], [8] and [9]. The system is interconnected by means of communication links and allows utilities to increase revenue stream and facilitates more flexible generation dispatch. There are, however the following challenges to consider:

i. Calibrating the sensing equipment of these systems to confirm accuracy of measured data can be a very challenging and time consuming exercise.

ii. Depending on the volume of incoming data and the number of multiple stations, delays in arrival of information can introduce challenges to control engineers in real time. Operational constraints require decisions, such as shutting down a generator or deloading and de-energising a transmission line, to be made in approximately 30 -seconds.

iii. Enhancing line ratings of a particular power line may have significant effects on protection zone reach and back up overcurrent relay operation. Adjusting these relays may require site attendance, thus limiting application of this system at times.

\section{E. Remote measurement of line emergency ratings}

Researchers in [10] commissioned a study to investigate short term emergency rating (STR) and long term rating (LTR) using a power donut device as shown in Fig. 1 to help system operators continue supplying power to customers during high loading conditions. Unlike many studies, the authors of [10] were able to distinguish between long and short term emergency ratings. Although both rely on the thermal time constant of the overhead line conductor material, the line preloading conditions is of great importance in determining the LTR and STR Although the authors stated that long term emergency rating (LTE) and short term emergency rating (STE) can be computed each minute, it would be impractical to compute line rating minute by minute because the time taken to dispatch a coal fired generation plant will be in excess of 6 hours for a cold start plus at least an hour to synchronise at full load to the grid system's frequency.

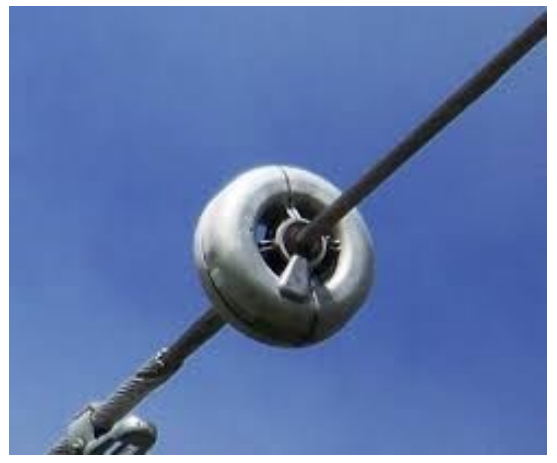

Fig. 1. Power donut transmits measured data to the main control centre

\section{TYPES OF OFF-LINE AMPACITY COMPUTATION}

A. Statistical line rating computation method based on historical weather data

Researchers in [11] and [12] investigated the practical limitations on the use of a statistical method to compute power lines thermal ratings using historical weather data. This is reliant on the relationship between the line ratings corresponding to given ambient temperatures being known. They discussed the impact of span orientation on its thermal capacity, for reasons such as wind speed and direction. They also considered the impact of shielding effect of trees and buildings in urban communities on transmission lines thermal capacities. The work gave an approximate quantification and briefly described the impact of thermal time constants of 
Overhead Line (OHL) wires. These figures are particularly important when determining the acceptable transient thermal overloading duration "short term emergency rating" at any given temperature, e.g. $95^{\circ} \mathrm{C}$ for 5 minutes for an AAAC (All Aluminium Alloy Conductor) based conductor. It is also important to distinguish this limit from the acceptable loss of life limit that system operators are pressured to accept during extreme weather conditions and system emergencies.

\section{B. Hybrid statistical/real-time weather parameter line rating method}

A different statistical method is described in [13]. This study predicts the thermal overload risk on any given conductor at one hour ahead, based on current known weather conditions and power system operating conditions. A weather monitoring system strung along the transmission line aids in making operational decisions that affect line loading. It should be noted that the conductor hardware age/condition, switchgear thermal constraints, thermal overload ratings of protection relays were not considered by authors, generally these can be the limiting factors in transmission system.

\section{Iterative method of computing transfer capability of an interconnected transmission system}

Researchers who conducted study [14] aimed to compute the transfer capability of an interconnected transmission system taking into account factors such as predicted network response and listing all potential system risks. The study attempted to solve transfer capability of an interconnected transmission system through an iterative method and to perform a sensitivity analysis to capture all non-linear regions.

\section{Static line rating computation method}

IEEE 738 standard [15] presents an algorithm to compute the overhead power conductor ampacity. This algorithm is based on a mathematical model of heat gained (heating) and heat lost (cooling). It does not take into consideration factors such as variation in temperature of a live conductor due to factors such as dust, snow or rain.

In [1] the researchers took a practical approach to compute line rating. A laboratory-based experiment was performed to investigate the effect of wind speed on the cooling of a section of an Aluminium Conductor Steel Reinforced (ACSR) "Lynx $175 \mathrm{mSq}$ " conductor under controlled environmental conditions. The physical experiment proved that the impact of both wind speed and direction are of significance to the cooling rate. The work also assessed individually the impact of wind speed, wind attack angle and ambient air temperature on the conductor's temperature. The drawback to this experimental investigation is that it assumed solar heating to be negligible.

\section{SUMMARY AND CONCLUSIONS}

The selection of ampacity identification technique to be employed to calculate ampacity of a particular circuit depends on many factors, such as criticality of the line to the system and the topography of the area through which the circuit runs, the expected duration of the event, etc. The system operator will need to perform a detailed cost-benefit analysis to determine whether the additional stress resulting from operating beyond defined parameters on a case by case basis. It will be useful to employ more than one technique to ensure accuracy is achieved because there is no agreed single technique which can provide a comprehensive solution. Future work in this area will investigate the impact of the environmental conditions on the heating/cooling rate for $\mathrm{OHL}$ conductors, in order to improve upon existing methods.

\section{REFERENCES}

[1] J Fu , S.Abbot , B.Fox , D.J. Morrow And S.Abdelkader, "Wind Cooling Effect on Dynamic Overhead Line Ratings", Published in 45th Int'1 Universities Power Engineering Conference (UPEC), 2010

[2] V T. Morgan ; National Measurement Laboratory, CSIRO “The Loss of Tensile Strength of Hard-Drawn Conductors by Annealing in Services" (Volume:PAS-98, Issue: 3)

[3] T 0. Seppa, "Accurate Ampacity Determination: Temperature - Sag Model for Operational Real Time Ratings", IEEE Trans Volume:10, Issue: 3, July 1995

[4] D.A.Douglas \& Abdel-Aty EdriReal "Time monitoring and dynamic thermal ratings", IEEE Trans Power Delivery, Volume:11, Issue: 3, 1996

[5] C Mensah-Bonsu, U F Krekeler, G T Heydt, Y Hoverson, J Schilleci, and B L. Agrawal, "Application of global positioning system to the measurement of overhead power transmission conductor sag" IEEE Trans Power Delivery, Volume:17, Issue: 1, 2002

[6] K.E.Holbert \& G.T.Heydt "Prospects for dynamic transmission ratings" , IEEE Int'l Sym Circuits and Systems, 2001. ISCAS 2001 Volume:3, May 2001

[7] S.D.Foss \& R.D.Maraio "Dynamic Line Rating in the Operating Environment" IEEE Trans Power Delivery, Volume:5, Issue: 2, 2002

[8] R Adapa \& D.A.Douglas "Dynamic thermal ratings monitors and calculation methods" IEEE Power Engineering Society Inaugural Conference and Exposition in Africa, July 2005

[9] M. W. Davies, "A new thermal rating approach; the real time thermal rating system for strategic overhead line conductor transmission lines" IEEE Trans Power Apparatus and Systems, Volume:96, Issue: 3, March 2006

[10] J.S.Engelhardt \& S.P.Basu "Design, installation and field experience with an overhead transmission dynamic line rating system" IEEE Transmission and Distribution Conference, 1996.

[11] D.A.Douglas, "Weather dependant versus static thermal rating" IEEE Trans Power Delivery, Volume:3 , Issue: 2, April 1988

[12] W. J. Steeley, B. L. Norris and A. K. Deb, “Ambient Temperature Corrected Dynamic Transmission Line Ratings at Two PG\&E Locations" IEEE Trans Power Delivery, Volume:6, Issue: 3, July 1991

[13] Jun Zhang, Jian Pu, J D. McCalley, H Stern, and W A. Gallus “A Bayesian Approach for Short-Term Transmission Line Thermal Overload Risk Assessment" IEEE Trans Power Delivery, Vol:17 , Issue: 3, July2002

[14] P W. Sauer, "Technical Challenges of Computing Available Transfer Capability (ATC)in Electric Power Systems" 45th Int'l Universities Power Engineering Conference (UPEC), Cardiff, Wales, September 2010

[15] IEEE738-Standard for calculating current-temperature relationship of bare overhead conductors, IEEE Std. 2012 